\title{
The Relationship Between Market Orientation And Marketing Information Systems Effectiveness: An Empirical Investigation
}

George G. Panigyrakis, (E-mail: pgg@aueb.gr), Athens University of Economics and Business, Greece Kalliopi C. Chatzipanagiotou, (E-mail: khatzip@aueb.gr), Athens University of Economics and Business, Greece

\begin{abstract}
A growing body of literature has stressed the importance of market orientation in explaining and understanding different aspects of companies' practices. However, little research has been done regarding the relationship between market orientation and marketing information systems effectiveness. The findings would seem to suggest that market orientation has a significant impact on the effectiveness of marketing information systems. Furthermore, the results suggest that external dimensions of market orientation, such as customer orientation and competitor orientation related to the external dimensions of marketing information systems effectiveness such as productivity, efficiency. Similarly, the internal market orientation dimension such as interfunctional coordination are significantly and positively related to internal dimensions of marketing information systems effectiveness such as information management, internal communications. At the end, study limitations and future research directions are discussed.
\end{abstract}

\section{Introduction}

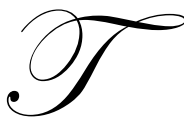

he modern business environment is highly competitive. The market' globalization, the plethora of products and services, the new channels of communication, force marketing executives to make decisions in a continuously transforming environment. The key to such successful decisions is the effective management of the internal and external information.

It's this very same need for the collection of data marketwise, its diffusion as well as its proper utilization by the various departments of a company, that Kohli and Jaworski (1990) underline when they study the meaning of the market orientation.

Needless to say, there are other researchers, such as Narver and Slater (1990) who basically agree with the point of view of Kohli and Jaworski (1990), when they point out that a market oriented company should gather information on the needs, preferences and the specific characteristics of its customers.

Apart from that, the same company should be aware of its competitors' strategic movements and finally, it should respond to the complicated problems that arise, based on this information and the co-operation of the departments/functions within the company.

Towards effective management of the internal and external information, many authors ((Markku et al., 1993, Leverick et al., 1997, Talvinen 1995, Webster, 1993) believe that companies should turn to the evaluation of Information Technology and especially, to marketing information systems. The use of these systems helps the company with the plethora of data management, thus enforcing its capacity to be aware of and satisfy its customers' needs, to co-operate with its suppliers and to control its activities (Talvinen, 1995). 
Though the aforementioned may suggest that the Information Systems are the main infrastructure on which the implementation of market orientation philosophy is based, the literature shows major research deficiencies when studying the relation between market orientation and marketing information systems and in specific their effectiveness.

This article aims to study the aforementioned relationship and in specific the detection of market orientation dimensions that strengthen the effectiveness of the marketing information systems.

This paper itself is organised as follows. Firstly, the conceptual framework underpinning the study is presented. Then a formal hypotheses based on the reviewed literature is developed. This is followed by the methodology used to test hypotheses. The paper then terminates with the testing of the hypotheses and finally the discussion of results, the limitations of the study, as well as suggestions for further research.

\section{Market Orientation}

\section{Definition of market orientation}

During the 1990's a great part of research activity, was focused on the detection of the most important dimensions, of the market orientation definition. Most studies refer to market orientation as the materialization of the marketing definition, consisting of two basic aspects: First, the adoption of a specific company's philosophy/way of thinking when referring to the content of the marketing definition (Hooley et al.1990; Deshpante et al, 1993; Deng and Dart, 1994) and second, the application of specific business activities and marketing practices regarding the promotion, sales, pricing and distribution network organization, etc (Narver and Slater 1989; Kohli et al.1992; Diamantopoulos and Hart 1993; Greenlay 1995).

Hooley (1990) in specific, asserts that -based on its philosophical aspect- market orientation should be studied as a general business mentality that sets guiding lines, distributes knowledge and leads the company to some specific marketing behavior.

Kohli and Jaworski (1990), point out the company's need for data gathering and evaluation in regard of the current and future customers' needs.

They underline that the company's various departments must have information on the market, to be able to successfully respond to arising complicated problems. Within this framework, the market orientation emerges from a behavioral perspective which includes three main activities: a) the data collection and evaluation of the market on behalf of the company b) the distribution of this data amidst the company's various departments c) the company's response according to the aforementioned information

Specifically, the data concerns the current and future needs of the customers and the way in which these needs are affected by exogenous factors, such as the competition, technology, governmental regulations, etc.

They also mention that the said data collection and the knowledge implementation are not the liability of one department in the company (e.g. marketing dept.) but of the company as a whole. Besides, neither the information required nor its nature (e.g. orders, sales, prices, costs, payments, etc) justifies data collection by the marketing dept.

The data distribution on market orientation includes the relative briefing of executives, regardless the department they belong to, in order to achieve set goals according to a clear market orientation (e.g. customers' satisfaction and retention, marketing prevalence against that of the competition, etc.).

Finally, the company's response is measured on its ability to actually evaluate this information, i.e. to plan and implement marketing steps on a strategic and ordinal level based on the market's actual conditions, as they reflect on the information gathered. 
Some other researchers, such as Narver and Slater (1990), basically agree with Kohli and Jaworski (1990), who present three main aspects of the market orientation a) customer orientation, which is the understanding of the customer's needs, preferences and special characteristics (Day and Wensley, 1988), currently and optionally in the future. b) competition orientation, which is the company's ability to understand the short term strengths and weaknesses as well as long term abilities and strategies of both current and optional competitors, (Aaker 1988, Day and Wensley 1988, Porter 1980,1985) and finally, c) the co-ordination of the partial departments and functions of a company, concerning the co-ordination of all the resources and the evaluation of all available data, towards the addition of value for the customer's interest (Narver and Slater, 1989).

So far, all the alternative definitions taken into consideration (Tuominen et al. 1999), have led to three main aspects of which market orientation is formed (Day, 1994a):

- $\quad$ The total of a company's values primarily concerning its customers

- The company's ability to gather, distribute and evaluate the best available information on its customers and competitors

- The co-operation amidst the company's various departments for the evaluation of the available information towards the establishment of added value for the customer's interest.

\section{Fields of research in regard to market orientation}

During the last ten years, researchers tried to clarify the meaning and the role of a market oriented company. This resulted in the following relative issues:

- $\quad$ The measurement of market orientation (Kohli and Jaworski,1990; Narver and Slater 1990; Gray et al. 1998; Matear et al. 1997; Mavondo, 1999; Selnes et al., 1996)

- $\quad$ The intro-business pre-suppositions of market orientation (Huddleston and Good, 1999; Jaworski and Kohli, 1993; Ruekert, 1992), such as, the organizational structure, organizational climate, conflict coordination, top management emphasis.

- The market orientation effect on the company's revenues. This study included measurements, such as: return on assets (Narver and Slater, 1990), return on investment (Hooley, Lynch and Shepherd, 1990), profitability, size, market share and growth (Deshpande, Farley, Webster et al., 1993), return on investment, new product success and sales growth (Greenley, 1995).

- $\quad$ The market orientation effect on marketing effectiveness (Deshpandé and Webster 1989, Hofstede, 1998, Trice and Beyer, 1993, Webster, 1995, Deshpandé and Farley, 1999, Liesen et al. 2002).

Even though the market orientation role in several business environments has been extensively studied, there is no research on the relation between market orientation and marketing information systems and specifically the effectiveness of the said systems. The two means seem to colligate, since the information systems technology contains the main infrastructure on which the materialization of the market orientation philosophy has been based until now (Narver and Slater, 1990, Kohli and Jaworski, 1990).

\section{The effectiveness of Marketing Information systems}

\section{The definition of marketing information systems}

The marketing information systems mainly emphasises adoption of the basic aspects of market orientation (Kohli and Jaworski, 1990).

More specifically, the first relative definition was set in 1967 by Cox and Good, who mention that marketing information systems are a total of procedures, analysis methods and data presentation, used in marketing decisions. In the years to follow, there were many (Brien and Stafford 1968, Smith et al.1968, Buzzell et al.1969) who tried to expand the said definition underlining that marketing information systems are comprised of information on control, planning and research activities. This being the reason why they should be relatively categorized. 
More recent research (Kotler 1994, Li 1995) presents a rather complete definition, by emphasising the fact that the marketing information system, is the total result of many persons, equipment and procedures aiming towards the collection, process, analysis, assessment and distribution of required and correct information for marketing decision makers.

\section{Their effectiveness}

Even though the definition and the activities the marketing information systems currently deal with have significantly increased, the study of the literature presents many deficiencies regarding the methods of measurement and effectiveness of such systems.

Nevertheless, the Competing Values Model is a rather interesting exception to the rule. This was proposed by Quinn and Cameron (1983) and Quinn and Rohrabugh (1983).

Cooper and Quinn (1993) have suggested its use for the assessment of management information systems, while Sääksjärvi and Talvinen (1995) use the Competing Values Model to measure the effectiveness of marketing information systems.

Principally, this model is based on the basic admittance that the mean of effectiveness is not an onedimensional mean, but a complex of means (Cameron, 1978), i.e. it is composed of a number of partial means such as return, productivity, information management, flexibility, etc.

Quinn and Rohrbaugh (1983) present 16 criteria for the assessment of a business's effectiveness.

To be more specific, according to the research of Quinn and Rohrbaugh (1983), an organization may be examined by employing a triple axis: a) focus, b) structure, c) means-ends.

Figure 1

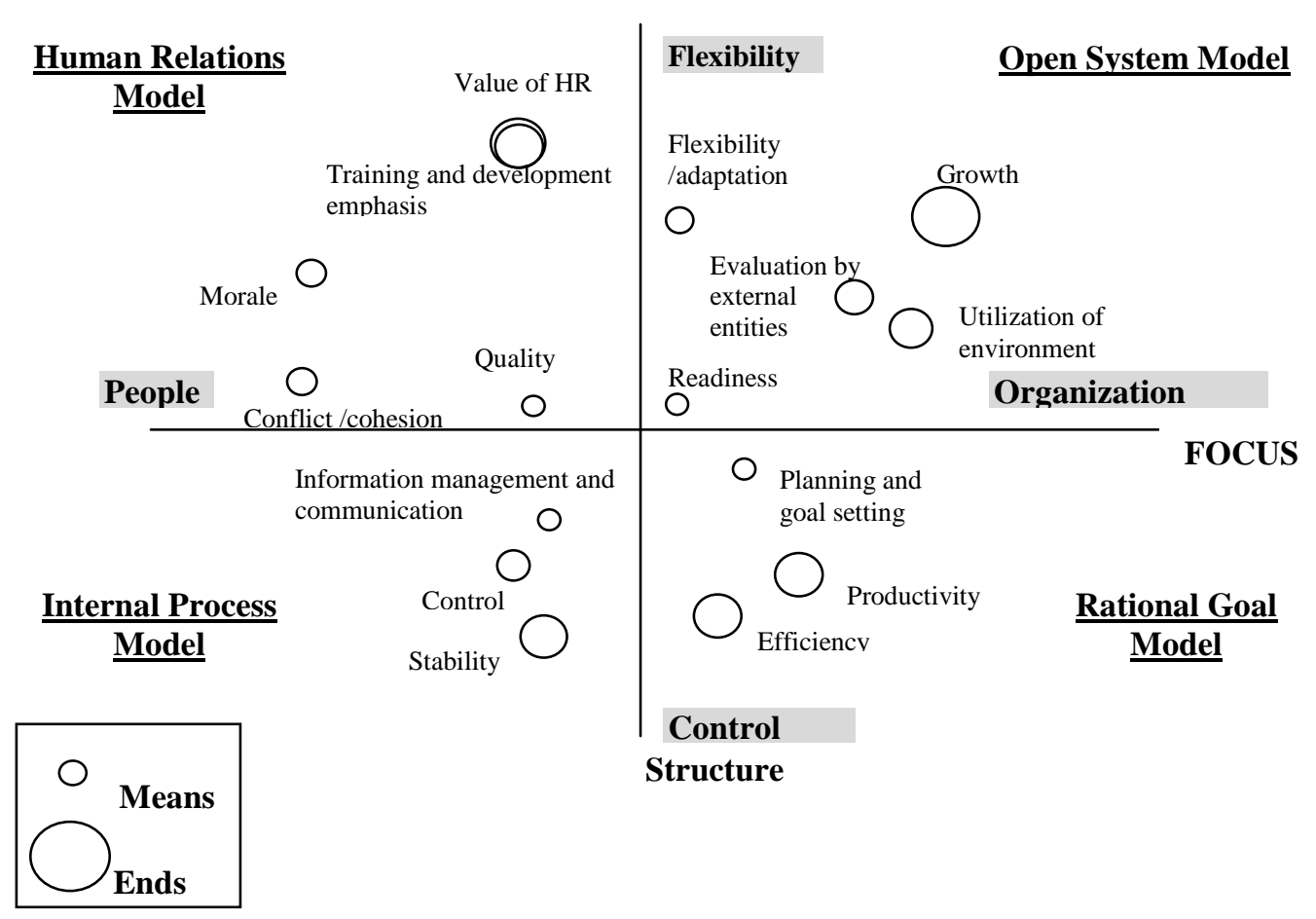

Figure 1. Competing values framework: Effectiveness Criteria

Source: Quinn, R.E., Rohrbaugh, J., 1983, "A spatial model of effectiveness criteria: towards a competing values approach to organizational analysis", Management Science, Vol. 29, 363-77. 
The focus dimension reflects various business management differences. On the one hand, it presents the focused company, which tries to be effective through the improvement of its internal procedures (micro emphasis), the management and the evolvement of its employees' relations, while on the other hand it presents the focused company that tries to be effective through its external procedures (macro emphasis) and in particular its flexibility to successfully respond to the market's needs.

The structure presents the differences amidst the various organizations regarding the adoption of a specific mentality with main concern, on the one hand, the flexibility and the response within a continuously evolving competitive environment, while on the other hand, the stability and the monitoring of the procedures and the regulations of a company.

The third dimension presents the differences amidst the various organizations regarding the way they perceive the means in relation to their ends, i.e. on the emphasis given on the programming and planning of a goals achievement (important processes) and conversdly, on the emphasis given on the final results (Final outcome).

These three axis aim to define the four models of business activity evolvement: Human Relations; Open System; Internal Process; Rational Goal Model (Quinn and Rohrbaugh, 1983).

Quinn and Rohrbaugh (1983) believe that in order for a company to be effective, it should be able to function properly within the framework for all four models.

\section{Figure 2}

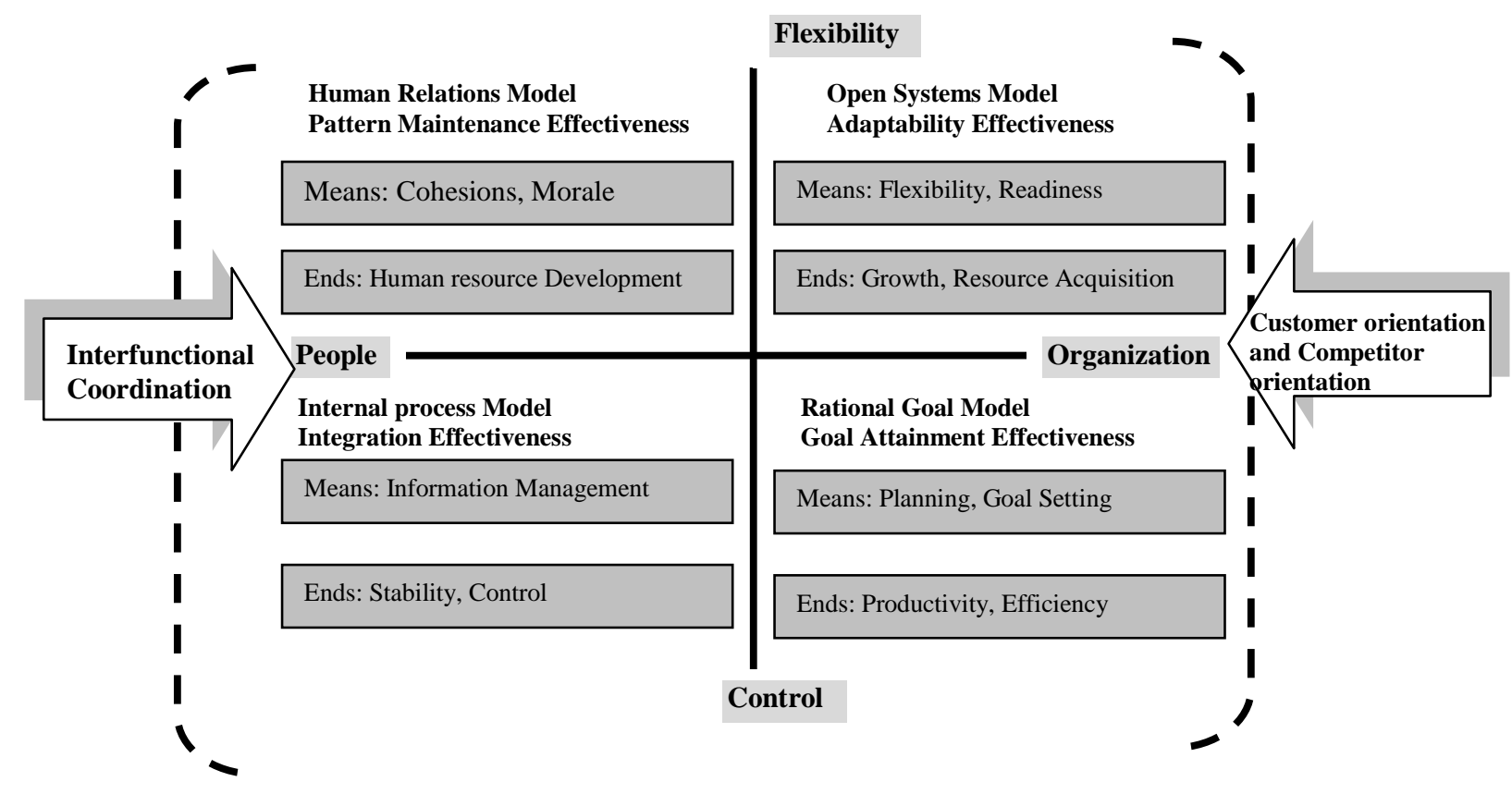

Nevertheless, they state that all the aforementioned models cannot co-exist at the same level within an organization. The key to an organization's successful effectiveness is its ability to balance those values.

As Sääksjärvi and Talvinen (1995) underline, the information systems' technology may contribute to effectiveness through the four basic dimensions emerging from the Quinn and Rohrbaugh (1983) Model. More specifically they mention that: 
- The flexibility and the readiness to respond to the external environment (Open System Model) that a company acquires through specific applications of information systems leads it to, a better market monitoring, the improvement of the customers' satisfaction, the sales increase, the upgrading of its knowledge for its customers' needs

- The marketing information systems lead to the improvement of a company's human relations (Human Relations Model), which results from the most usual effective marketing activities and the promotion of the communication amidst the marketing department staff.

- A better information management (Internal Model Process) is guaranteed by the information systems' applications. Applications such as the marketing report system, decision support system and marketing control system, lead to the planning of more productive/effective marketing procedures in rapport to the improvement of the decision making procedure and the monitoring of marketing activities, and finally,

- The return and the productivity (Rational Goal Model) of a company through marketing information systems, results in the improvement of the functional procedures with emphasis given on the reduction of the operational and administrative cost and the development of the productive time. The use of specific sub-systems such as: marketing planning systems, marketing intelligence system, marketing research system, marketing decision support systems, etc, leads to the improvement of the marketing planning programs' procedures as well as to the implementation of these very same programs.

Until now, it seems that information technology reinforces the improved effectiveness as it contributes to information processing and distribution for the marketing decision makers, regardless of the management level (Webster, 1994 a). Furthermore, the data gathering, processing and evolvement (Kohli and Jaworski, 1990) both on an internal and an external level, may decide the orientation of a company and sustain it effectively.

The aforesaid leads to the conclusion that market orientation should have a positive relation with marketing information systems. This since the adoption of specific behaviours based on the recognition of the need for marketing information systems, form certain conditions for these systems' use and implementation. Therefore the proper conditions for their effectiveness. in specific:

We presume that market orientation is positively connected to the information systems' effectiveness and

H1: The more a company is market oriented, the more the marketing information systems' effectiveness is increased.

Furthermore, the examination of which specific dimensions of market orientation are connected to dimensions in the marketing information systems effectiveness, would be very interesting.

\section{Internal and External dimensions of market orientation}

According to the reasoning of Liesen et al. (2002), one has to deal with the internal and the external dimensions of a market orientation.

More specifically, they sustain that the coordination for example, of several departments may be considered as an internal dimension of the market orientation, since it refers to the company's ability to internally diffuse resources amidst the various departments of a company, thus aiming at the establishment of a greater value to the interest of the customer.

Conversely, the customer orientation and the competition orientation (Narver and Slater, 1989) are the two dimensions which enable the company to be informed on the customers' needs (current and future ones) as well as its competitors' movements (Webster, 1994b). Through these two dimensions, the company strengthens its contact and communication with the market factors. Thus, one could think that these dimensions reflect the internal dimensions of the market orientation (Liesen et al. 2002), i.e. dimensions that orientate the company to the extraorganizational environment, the market. 
Since the internal and external dimensions of the market orientation, have been shown one should also detect the corresponding dimensions of the marketing information systems' effectiveness.

\section{Internal and External dimensions of marketing information systems effectiveness}

The internal and external dimensions of the marketing information systems' effectiveness results from the structure of Competing Values Model by Quinn and Rohrbaugh (1983).

More specifically, on the horizontal axis (of focusing) the Internal Process Model and the Human Relations Model (Figure 2), refer to the development of relations among the marketing department employees, as well as to the better management of information within the organization, thus they may be considered as forming the internal dimension of the marketing information systems' effectiveness (Quinn and Rohrbaugh, 1983).

Thus, we presume that co-operation among the departments/functions of the company which constitutes the internal dimension of the market orientation (Liesen et al., 2002), is positively connected to the internal dimension of the marketing information systems' effectiveness (Internal Process Model, Human Relations Model).

H2: The higher the co-operation degree among the departments/functions, the higher the level of the internal dimension of the marketing information systems' effectiveness.

The external dimension of the marketing information systems' effectiveness is referred to as the Rational Goal Model, Open System Model (Figure 2) where the company focuses its effort on being productive, cost effective, and effective in general, through its flexibility and readiness to respond to market needs and the external environment (Quinn and Rohrbaugh, 1983).

Therefore, one way assume that the more a company perceives its customers' needs and preferences along with its competitors' movements and strategies, the more its ability in analyzing, planning and implementing marketing programs in the most cost effective way, is increased. Moreover, it acquires the ability to flexibly and immediately respond to the satisfaction of customers, the basic, primary goal.

Thus one assumes that the customer and the competitor orientation that consist the market orientation's external dimension (Liesen et al. 2002) are positively connected to the external dimension of the marketing information systems' effectiveness. More specifically, the results of this research are the following:

H3: The greater the customer orientation, the higher the level of the external dimension of the marketing information systems' effectiveness.

H4: The greater the competitor orientation, the higher the level of the external dimension of the marketing information systems' effectiveness.

\section{Methodology}

Sample Definition

The sample was collected from executive personnel working in Tourism companies in Greece and in specific five stars hotels. The selection of this field was based on the fact that the relative information highly contributes to and justifies the great adoption of information technologies on behalf of all interested parties, i.e. the providers and the consumers of tourism services.

In measuring the variables of interest for this study, established and validated scales ere employed in every case. However, given that the original scales were developed in a language other than that in which the instrument would be administrated, English, a native speaking employee of the British Council located in Athens, who has been living and working in Greece for over 15 years and is also fluent in Greek language, was involved in translating the 
scales in to Greek. Secondly, during the development phase of the research instrument 5 senior Hotel Managers were contacted. They agreed to provide assistance with regard to the wording of the items and their relevance to the tourism industry as well as with regard to slightly enriching the scales by adding items, which, according to their expert opinion, would provide a more comprehensive conception of the notions under investigation.

The result of the said effort was the planning of a detailed questionnaire. Prior to its dispatch, the questionnaire was thoroughly checked (pilot-checking) in order to increase the content validity of the research instrument. For this purpose, there were 50 personal interviews with hotel managers, the representative of which, agreed to participate and add their own comments. These personal interviews were used to further improve the phrasing of questions and the scales used in the research.

The questionnaires were then mailed to 780 five star hotels, all over Greece. A total of 53 were returned void, due to various reasons (address unknown, temporary shut down because of expansions, refurbishment, etc), which reduced the active population to 727 hotels. Finally, 254 hotels responded which lead to a 34, 9\% response rate.

\section{Variables Measurements}

The market orientation was measured according to the Narver and Slater (1990) scale. More specifically, using a 7-points scale ranging from 1= "I strongly disagree" to 7= "I strongly agree").

The validity of the three scales that constitute the market orientation were checked by Cronbach's alpha reliability coefficient for each one of the different dimensions' scales (Nunnaly and Bernstein, 1994) who proved that the scales which were used are internally coherent (internal consistent) and reliable (customer orientation $a=0,761$, competitor orientation $a=0,823$, coordination of the departments $a=0,727$ ).

The marketing information systems' effectiveness was based on the Competing Values Model (Quinn and Cameron, 1983; Quinn and Rohrbaugh 1983) and in specific on Sääksjärvi and Talvinen (1995) project.

Adapting the suggestions of executives who helped in the development of the research instrument, the scales were enriched with other questions regarding the marketing information systems' effectiveness in relation to certain dimensions of the marketing mix, such as the promotion, communication, pricing, etc. These additions do not divert from Competing Values Model. The scale included 28 questions ("items") and the respondents had to answer on a 7-points scale (ranging from 1= "I strongly disagree" to 7= "I strongly agree"). For the detection of the major factors an exploratory factor analysis was made. The upper goal of this analysis is the examination of the factorial structure of the measurements and the dimensions of the scales. From the results we excluded questions ("items") with factor loadings of less than 0,40 . Furthermore, in the cases where the deletion of certain questions was causing a significant increase in the creditability coefficient, the said questions were also not included in the analysis.

In table 1, the partial "items" that constitute every measurement factor of the information systems are summarized with the corresponding factor loadings.

Resulting from table 1 , the exploratory factor analysis led to the detection of four factors that collectively construe $82,6 \%$ of the total fluctuation of the initial variables. The factor analysis was made according to the method of the rotation of the factorial Varimax solution. The control of the data suitability for the implementation of the factor analysis was made by using both the sufficiency criterion of Kaiser, Meyer, and Olkin (KMO) sampling, which on this occasion is 0,896 , and the Bartlett orbicular (sphericity) criterion, which in this specific case is statistically significant.

Table 2 shows the results of the scales' reliability measurement of the marketing information systems effectiveness, which was checked again by the Cronbach's alpha reliability coefficient.

Furthermore, table 2 shows the results of the descriptive statistics for every "item." 
Table 1: Exploratory Factor Analysis of the Marketing Information Systems Effectiveness Dimensions

\begin{tabular}{|c|c|c|}
\hline Factors Produced by the Analysis & Items Loading in Each Factor & Loadings \\
\hline \multirow{4}{*}{$\begin{array}{l}\text { Factor 1: Internal Process Model } \\
\text { (Explaining 27,009\% of total variance) }\end{array}$} & Improved control & 0.894 \\
\hline & Improved marketing planning & 0.681 \\
\hline & Improved marketing reporting & 0.896 \\
\hline & Improved decision making & 0.684 \\
\hline \multirow{3}{*}{$\begin{array}{l}\text { Factor 2: Human Relation Model } \\
\text { (Explaining 26,574\% of total variance) }\end{array}$} & Time saving, lower level of routine work & 0.747 \\
\hline & Improved sales work and customer service & 0.986 \\
\hline & Improved internal communication & 0.663 \\
\hline \multirow{4}{*}{$\begin{array}{l}\text { Factor 3: Open Systems Model } \\
\text { (Explaining 22,028\% of total variance) }\end{array}$} & Improved market sensitivity & 0.657 \\
\hline & Improved customer satisfaction & 0.592 \\
\hline & Improved sales & 0.597 \\
\hline & Improved customer knowledge & 0.824 \\
\hline \multirow{4}{*}{$\begin{array}{l}\text { Factor 4: Rational Goal Model } \\
\text { (Explaining 7,003\% of total variance) }\end{array}$} & Marketing programmes cost savings & 0.712 \\
\hline & Quickest development of new services in the market & 0.758 \\
\hline & Improved sales promotion activities & 0.794 \\
\hline & Direct and more effective marketing research & 0.864 \\
\hline $\begin{array}{l}\text { Kaiser-Meyer-Olkin Measure of Sampli } \\
\text { Bartlett's Test of Sphericity: } X^{2}=4210, \\
\text { Total Variance explained: } 82,614 \%\end{array}$ & 0.896 & \\
\hline
\end{tabular}

Table 2. Descriptive Statistics for Marketing Information Systems Effectiveness

\begin{tabular}{|c|c|c|c|}
\hline Scales & Dimensions & Mean & Std. Deviation \\
\hline \multirow{4}{*}{$\begin{array}{l}\text { Internal Process Model } \\
(\alpha=0,835)\end{array}$} & Improved control & 5,87 & 1,28 \\
\hline & Improved marketing planning & 5,61 & 1,07 \\
\hline & Improved marketing reporting & 5,98 & ,76 \\
\hline & Improved decision making & 5,85 & ,91 \\
\hline \multirow{3}{*}{$\begin{array}{l}\text { Human Relation Model } \\
(\alpha=0,831)\end{array}$} & Time saving, lower level of routine work & 5,83 & ,88 \\
\hline & Improved sales work and customer service & 5,97 & 5,47 \\
\hline & Improved internal communication & 5,03 & ,96 \\
\hline \multirow{4}{*}{$\begin{array}{l}\text { Open Systems Model } \\
(\alpha=0,925)\end{array}$} & Improved market sensitivity & 5,65 & 1,05 \\
\hline & Improved customer satisfaction & 5,86 & ,97 \\
\hline & Improved sales & 5,60 & 1,10 \\
\hline & Improved customer knowledge & 5,92 & 1,21 \\
\hline \multirow{4}{*}{$\begin{array}{l}\text { Rational Goal Model } \\
(\alpha=0,937)\end{array}$} & Marketing programmes cost savings & 5,54 & 1,57 \\
\hline & Quickest development of new services in the market & 5,13 & 1,81 \\
\hline & Improved sales promotion activities & 5,20 & 1,94 \\
\hline & Direct and more effective marketing research & 4,84 & 1,91 \\
\hline
\end{tabular}

As shown in the table, the scales are reliable and in specific, giving Internal Process Model $(a=0,835)$, Human Relations Model ( $a=0,831)$, Open System Model $(a=0,925)$ and finally Rational Goal Model $(a=0,937)$.

\section{Data Analysis and Findings}

For the examination of the cases various regression analyses were run. More specifically, H1 examines whether there is a positive relation between market orientation and marketing information systems' effectiveness. 
The dependent variable of the multiple regression analysis is the effectiveness of the marketing information systems and the three dimensions of the market orientation are the independent variables.

Whether the relations of the dependent with the independent variables were satisfying the linearity through the scatter diagrams use where checked prior to regression analysis. It was ascertained that there were not any intense non-linear relations. Another significant issue that should be examined was the multicollinearity, i.e. the detection of high correlations among the independent variables and that only because it was given that all three independent variables are the partial dimensions of the same size, of the market orientation. Nevertheless, as shown in table 3, the biggest correlation noted does not exceed 0,614, very much below the acceptable limit of 0,90 (Hair et al. 1998). The table 4 shows the results of the analysis.

Table 3: Pearson's Correlation Coefficients

\begin{tabular}{|c|c|c|c|}
\hline & $(1)$ & $(2)$ & $(3)$ \\
\hline Customer Orientation (1) & $\mathbf{1 , 0 0 0}$ &, $369^{* *}$ &, $618^{* *}$ \\
\hline Competitor Orientation (2) &, $369^{* *}$ & $\mathbf{1 , 0 0 0}$ &, $426^{* *}$ \\
\hline Interfunctional Coordination (3) &, $618^{* *}$ &, $426^{* *}$ & $\mathbf{1 , 0 0 0}$ \\
\hline \multirow{2}{*}{ Correlation is significant at the 0.01 level (1-tailed). (N=254) } \\
\hline
\end{tabular}

As shown from the results of the Table 4 , the customer orientation $(p=0,007)$ and the competitor orientation $(\mathrm{p}=0,002)$ as well as the coordination of the departments are statistically significant $(\mathrm{p}=0,05)$. They positively affect the marketing information systems' effectiveness, which leads us to the acceptance of H1.

Table 4: Regression Coefficient of Market Orientation Dimensions with Marketing Information Systems Effectiveness as Dependent Variable

\begin{tabular}{|l|c|c|}
\hline Method & Standardized & $\begin{array}{c}\text { VIF } \\
\text { (Variance Inflation Factor) }\end{array}$ \\
\hline ENTER & Beta & \\
\hline (Constant) & 3,099 & $\mathbf{1 , 2 5 1}$ \\
\hline Customer Orientation & $\mathbf{0 , 2 1 0}$ & $\mathbf{1 , 1 4 3}$ \\
\hline Competitor Orientation & $\mathbf{0 , 2 1 4} *$ & $\mathbf{1 , 2 3 6}$ \\
\hline Interfunctional Coordination & $\mathbf{0 , 0 9 1} *$ & $\mathbf{0 , 2 0}$ \\
\hline Adjusted R Square & $\mathbf{8 , 3 2 1}$ & \\
\hline $\mathrm{F}$ & \multicolumn{3}{|l}{} \\
\hline \multirow{2}{|c}{$\mathrm{p}<0,050$} & Dependent: Marketing Information Systems Effectiveness \\
\hline
\end{tabular}

Nevertheless, the fact that the coordination of the departments appears statistically significant, may be possibly attributed to the fact that the tourist units examined have adopted a business mentality which implies a market orientation (Open System Model, Rational Goal Model) rather than the internal organizational procedures and the evolvement of its human resources (Internal Process Model, Human Relations Model).

Furthermore, the Adjusted R Square $=0,20$ factor even though not high is nevertheless statistically significant (significant at 0,000 level).

H2 examines the relation between the departments' coordination and the internal dimension (Internal Process Model, Human Relations Model) of the marketing information systems' effectiveness. The dependent variable of the regression analysis is the internal dimension of the marketing information systems' effectiveness and the independent variable the internal dimension of the market orientation, the departments' coordination. Table 5 shows the results of this analysis. 
Table 5: Regression Coefficient of Interfunctional Coordination with Internal Marketing Information Systems Effectiveness as Dependent Variable

\begin{tabular}{|l|c|}
\hline Method & Standardized \\
\hline ENTER & Beta \\
\hline (Constant) & 4,383 \\
\hline Interfunctional Coordination & $\mathbf{0 , 2 1 7 *}$ \\
\hline \multicolumn{2}{|c|}{ Adjusted R Square } \\
\hline Dependent: Internal Marketing Information Systems Effectiveness \\
\hline$* \mathrm{p}<0,050$ \\
\hline
\end{tabular}

As shown in the results of Table 5, the departments' coordination is statistically significant ( $\mathrm{p}=0,000$ level) sustained by $\mathrm{H} 2$.

H3 examines the relation between customer orientation and the external dimension of the information systems' effectiveness (Open System Model, Rational Goal Model). For the examination of this relation as estimation of the regression analysis with a dependent variable of the external dimension of the marketing information systems' effectiveness, the customer orientation was made. Table 6 shows the results of this analysis.

Table 6: Regression Coefficient of Customer Orientation with External

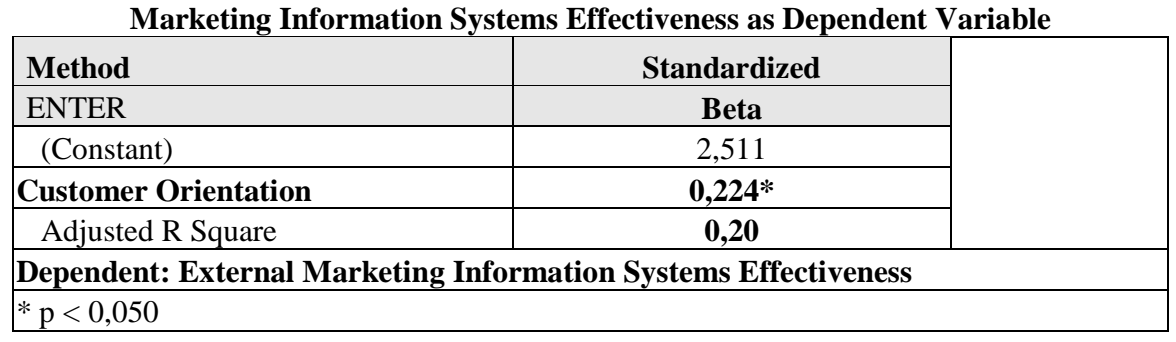

As shown in Table 6 , the customer orientation is statistically significant ( $\mathrm{p}=0,000$ level) which supports $\mathrm{H} 3$.

Similarly, $\mathrm{H} 4$ examines the relation between the competitor orientation and the external dimension of the marketing information systems' effectiveness (Open System Model, Rational Goal Model). For the examination of this relation an estimation of regression analysis with a dependent variable, the external dimension of the marketing information systems' effectiveness and an independent variable the external dimension of the market orientation, the competitor orientation was made. Table 7 shows the results of this analysis.

Table 7: Regression Coefficient of Competitor Orientation with External Marketing Information Systems Effectiveness as Dependent Variable

\begin{tabular}{|l|c|}
\hline Method & Standardized \\
\hline ENTER & Beta \\
\hline (Constant) & 4,119 \\
\hline Competitor Orientation & $\mathbf{0 , 2 4 1 *}$ \\
\hline Adjusted R Square & $\mathbf{0 , 2 5}$ \\
\hline Dependent: External Marketing Information Systems Effectiveness \\
\hline * p $<0,050$ \\
\hline
\end{tabular}

As shown in the results of Table 7, the competitor orientation is statistically significant (significant at 0,000 level) which supports $\mathrm{H} 4$. 


\section{Discussion and Implications}

This research wants to contribute to the examination of the relation of market orientation and marketing information systems' effectiveness, since the study of this relation presents significant research deficiencies, as shown in the literature review.

More specifically, the relations examined, concern: a) the relation of market orientation with marketing information systems' effectiveness, b) the relation of the internal dimension of the orientation according to the definition of the departments' coordination and the internal dimension of the marketing information systems' effectiveness, i.e. the dimensions regarding the Internal Process Model and the Human Relation Model, and c) the relation of market orientation and competitor orientation (external dimension of the market orientation) with the external dimension of the marketing information systems' effectiveness, i.e. the dimensions mentioned in the Open Systems Model and Rational Goal Model.

Therefore, it is significant that the company should recognize the fact that an investment in any type of marketing information system should enable it to keep pace with a high market orientation. This, since market orientation effects the way the company will obtain advantage and effectively use these systems, as shown from the results of the present study.

More specifically, the coordination of the departments contributes to the improvement of the marketing programs' monitoring and follow-up procedures, the reports' establishment procedures, and finally in the decision making procedure. Also, it reinforces the marketing activities under normal conditions, the communication among the marketing department personnel, and it promotes the services to the customer.

The customer orientation and the competitor orientation support the proper monitoring of the market and increases knowledge on customers' needs, thus helping the improvement of the customers' satisfaction. This also affects the sales increase, as well as the adoption of more cost-effective processes for the implementation of marketing activities in several levels, such as, new products development, sales management and market research.

\section{Limitations and Suggestions For Future Research}

This study is not free of limitations, which, nonetheless, future research may tackle. One first limitation is the specific industry sample (hotel), which may pose, constrains on the ability to generalize findings in the context of business-to-business services. This is particularly true especially for services since, to gain an overall perspective of the problems arising with the marketing of services, it is required to look across a broad cross-section of marketing situations (Lovelock, 1983). Thus, future research needs to be conducted to examine the findings of this study in other industries.

However, in doing so, caution is needed to avoid simplistic approaches in selecting industries and sample designs. As Lovelock (1983) has pointed out, our understanding of the marketing issues for services improves if we traverse traditional industry-specific categorizations and start thinking of classification schemes which capture issues like the nature of the service act, the type of the relationship the provider has with its customers, the nature of the demand and supply for the service, the possibilities for customization and the way the service is delivered. Hence, future research that will seek to examine our findings under a broader section of service circumstances should take these considerations into account and attempt to derive a research design which treats them adequately.

Finally the context of the study (Greece) is also a concern since it puts constraints on the generalizability of the results in other companies and other national contexts. Relationships in Southern Europe are handled in a different cultural context than that of Central and Northern Europe or the US. This may have an impact on the results of this study, particularly those pertaining to the relatively new relationships. Future research that replicates this study in other national contexts would be welcome. It would further improve our understanding of the relationship between market orientation and marketing information system effectiveness. 


\section{References}

1. $\quad$ Aaker, D. A., Strategic Market Management, $2^{\text {nd }}$ ed. New York, Wiley, 1988.

2. $\quad$ Brien, R.H. and Stafford, J.E., "Marketing information systems: a new dimension for marketing research", Journal of Marketing, Vol. 32, No. 3, pp. 19-23, 1968.

3. Buzzell, R.D., Cox, D.F. and Braun, R.V., "Marketing Research and Information Systems: Text and Cases", McGraw-Hill, New York, NY, 1969.

4. Cameron K., "Measuring Organizational Effectiveness in Institutions of Higher Education", Administrative Science Quarterly, Vol. 23, No. 4, pp. 604-632, 1978.

5. Cooper, R.B. and Quinn, R.E., "Implications of the competing values framework for management information systems", Human Resource Management, Vol. 32, No. 1, pp. 175-201, 1993.

6. Cox, D.F. and Good, R.E., "How to build a marketing information system", Harvard Business Review, Vol. 45, No. 3, pp. 145-54, May-June 1967.

7. Day, G. S. "The Capabilities of Market - Driven Organizations", Journal of Marketing, Vol. 58, pp. 37 52,1994a.

8. Day, G. S. and Wensley, R., "Assessing Advantage: A framework for Diagnosis Competitive Superiority", Journal of Marketing, Vol. 52, pp. 1-20, 1988.

9. Deng S. and Dart J., "Measuring Market Orientation: A Multi-Factor, Multi-Item Approach", Journal of Marketing Management, Vol. 10, pp. 725 - 742, 1994.

10. Deshpandé, R. and Farley, J. U. \& Webster, Jr. F. E., "Corporate Culture, Customer Orientation, and Innovativeness in Japanese Firms: A Quadrad Analysis", Journal of Marketing, Vol. 57, pp. 23 - 37, 1993.

11. Deshpande, R. and Webster, F.E. Jr., "Organizational culture and marketing: defining the research agenda", Journal of Marketing, Vol. 53, pp. 3-15, 1989.

12. Deshpandé, R., Farley, J.U., "Executive insights: corporate culture and market orientation: comparing Indian and Japanese firms", Journal of International Marketing, Vol. 7, No. 4, pp. 111-27, 1999.

13. Diamantopoulos A. and Hart S., "Linking Market Orientation and Company Performance: Preliminary Work on Kohli and Jaworski's Framework", Journal of Strategic Marketing, Vol. 1, No. 2, pp. 93-122, 1993.

14. Gray, B.J., Matear, S., Boshoff, C. and Matheson, P.K., "Developing a better model of market orientation", European Journal of Marketing, Vol. 32, No. 9, pp. 884-903, 1998a.

15. Greenlay, G., "Forms of Market Orientation in UK Companies", Journal of Management Studies, Vol. 32, No. 1, pp. 47-66, 1995.

16. Hair, Joseph f., Rolph E. Anderson, Ronald L. Tatham and William C. Black, "A Multivariate Data Analysis", $5^{\text {th }}$ edition, Prentice Hall, 1998.

17. Hofstede, G., "Attitudes, values and organizational culture: disentangling the concepts", Organization Studies, Vol.19, No.3, pp. 477-92, 1998.

18. Hooley, G. J. and Lynch, J. E. \& Shepherd, J., "The Marketing Concept: Putting the Theory into Practice", European Journal of Marketing, Vol. 24, No. 9, pp. 7 - 24, 1990.

19. Kohli A. J. and B. J. Jaworski, "Market Orientation: Antecedents and Consequences", Working Paper, Marketing Science Institute, Cambridge, Massachusetts, 1992.

20. Kohli A. J. and B. J. Jaworski, "Market Orientation: The Construct, Research Propositions and Managerial Implications", Working Paper, Marketing Science Institute, Cambridge, Massachusetts, 1990.

21. Kotler, P., "Marketing Management - Analysis, Planning, Implementation and Control", 9th ed., PrenticeHall International, London, 1994.

22. Leisen Birgit, Bryan Lilly, Robert D. Winsor, "The effects of organizational culture and market orientation on the effectiveness of strategic marketing alliances", Journal of Services Marketing, Vol.16, No.3, pp. 201-222, 2002.

23. Leverick, F., Littler, D., Wilson, D., Bruce., "The role of IT in the reshaping of marketing", Journal of Marketing Practice: Applied Marketing Science, Vol. 3, No. 2, pp. 87 -106, 1997.

24. Li, E.Y. "Marketing Information in the Top U.S. Companies: A Longitudinal Analysis," Information \& Management, Vol. 28, pp. 13-31, 1995.

25. Lovelock Chr., "Classifying Services to Gain Strategic Marketing Insights", Journal of Marketing, Vol. 47, No. 3, pp. 9-20, 1983. 
26. Markku, Sääksjärvi V.T. and Jari M Talvinen, "Integration and Effectiveness of Marketing Information Systems", European Journal of Marketing, Vol. 27, No. 1, pp. 64-77, 1993.

27. Mavondo,D., Felix, T., "Market Orientation: Scale Invariance and Relationship to Generic Strategies across Two Countries", Journal-of-Market-Focused-Management, Vol. 4, No. 2, pp. 125-143, 1999.

28. Narver, J.C. and Slater, S.F., "The Effect of Market Orientation on Business Profitability", Journal of Marketing, Vol. 54, pp. 20-35, 1990.

29. Nunnally J., and Bernstein I., "Psychometric Theory", 3th Edition, McGraw Hill, 1994.

30. Porter, M., "Competitive Advantage", New York: Free Press, 1985.

31. Porter, M., "Competitive Strategy", New York: Free Press, 1980.

32. Quinn, R.E., Cameron, K., 1983, "Organizational life cycles and shifting criteria of effectiveness: some preliminary evidence", Management Science, No.29, pp. 33-51, 1983.

33. Quinn, R.E., Rohrbaugh, J., "A spatial model of effectiveness criteria: towards a competing values approach to organizational analysis", Management Science, 29, 363-77, 1983.

34. Ruekert, R.W., "Developing a Market Orientation: An Organizational Strategy Perspective", International Journal of Research in Marketing, Vol. 9, pp. 225-245, 1992.

35. Smith, S.V., Brien, R.H. and Stafford, J.E., "Marketing information systems: an introductory overview", in Smith, S.V., Brien, R.H. and Stafford, J.E. (Eds), Readings in Marketing Information Systems, Houghton Mifflin, Boston, MA, 1968.

36. Talvinen, J.M. "Information Systems in Marketing. Identifying Opportunities for New Applications," European Journal of Marketing, Vol. 29, No. 1, pp. 8-26, 1995.

37. Trice, H.M., Beyer, J.M., "The Culture of Work Organizations", Prentice-Hall, Englewood Cliffs, NJ, 1993.

38. Tuominen, M., and Moller,K., "Market orientation: a state-of-the-art review", Proceedings of $25^{\text {th }}$ EMAC conference: Budapest, pp. 1161-1181, 1996.

39. Webster, C. "Marketing culture and marketing effectiveness in service firms", Journal of Services Marketing, Vol. 9, No. 2, pp. 6-21, 1995.

40. Webster, F.E., 1994a, "Defining the new marketing concept", Marketing Management, Vol. 2, No. 4, pp. 22-30, 1994a.

41. Webster, F.E., "Executing the new marketing concept", Marketing Management, Vol. 3, No. 1, pp. 8-15, 1994b. 